\title{
Effect of Copper (Heavy Metal) on Catla Fish
}

\author{
Manju Bhargavi. $A^{1}$, Brindha. $P^{1}$, llanchezhian. $T^{* 2}$, Ayyappan. $S^{3}$ \\ ${ }^{1}$ Mphil student in Biochemistry, Marudu Pandiyar College, Thanjavur, Tamilnadu, India. \\ ${ }^{2}$ Assistant Professor in Biochemistry, ACPM Medical College, Dhule, Maharashtra, India. \\ ${ }^{3}$ Reader in Biochemistry, CSI Dental College and Research Centre, Madurai, Tamilnadu, India. \\ *Corresponding author's E-mail: ilanbiochemistry@gmail.com
}

Received: 28-09-2021; Revised: 18-01-2022; Accepted: 25-01-2022; Published on: 15-02-2022.

\section{ABSTRACT}

Heavy metal contamination has been reported in aquatic organisms. These pollutants build up in the food chain and are responsible for adverse effects and death in the aquatic organisms. Fish are relatively sensitive to changes in their surrounding environment including an increase in pollution. Fish health may thus reflect, and give a good indication of the health status of a specific aquatic ecosystem. For this present study Catla catla fish was used. The bioassay tests were conducted to find out the LC50 values for different durations of exposure $(24,48,72$ and 96 hours). We observed that the highest concentration at which 100 percent mortality was observed within 24 hours was considered as the lethal concentration ( $24 \mathrm{~h} \mathrm{LC100)}$ ) and the lowest concentration at which 100 percent survival was observed by the end of 96 hours was considered as the sublethal concentration ( $96 \mathrm{~h} \mathrm{LCO})$. The mortality of fish decreased with decreasing concentration of heavy metals of copper. As soon as fishes were transferred from fresh water to lethal and sublethal concentrations of heavy metals of copper increased swimming activity was noted. At lethal concentration of heavy metals of copper the fishes showed erratic swimming activities and lost their balance. From these studies, it was evident that the rate of mortality increased with increasing concentration of heavy metals. Hundred percent mortality occurred at a concentration of 10-ppm copper.

Keywords: Catla fish, Copper (Cu), Heavy metal, Sublethal \& Toxicity.

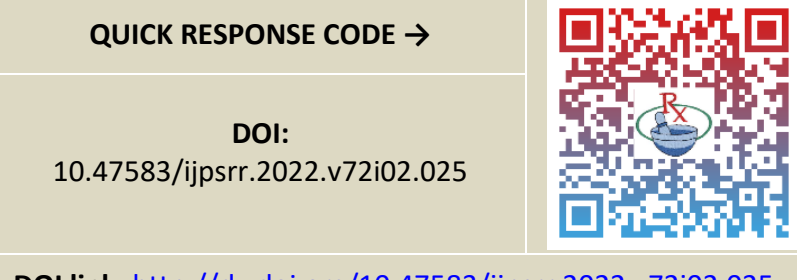

DOI link: http://dx.doi.org/10.47583/ijpsrr.2022.v72i02.025

\section{INTRODUCTION}

C opper is an essential trace metal in small concentrations for several fish metabolic functions. Essentiality of copper arises from its specific incorporation into a variety of enzymes, which play important roles in physiological processes (e.g. enzymes involved in cellular respiration, free radical defense, neurotransmitter function, connective tissue biosyntheses and other functions), as well as, into some structural proteins. $^{1}$

Although the crucial role of copper in several enzymatic processes, ${ }^{2}$ this heavy metal can exert adverse toxicological effects, when present in high concentrations in water. $^{3}$ In fact, it is potentially toxic when the internal available concentration exceeds the capacity of physiological detoxification processes.

Heavy metal contamination has been reported in aquatic organisms. ${ }^{4}$ These pollutants build up in the food chain and are responsible for adverse effects and death in the aquatic organisms. Fish are widely used to evaluate the health of aquatic ecosystems and physiological changes serve as biomarkers of environmental pollution. ${ }^{5}$

Heavy metals are present in effluents and some aquatic environmental from mining activities and industries that use these metals in various processes. Fish are an important source of human nutrition. Aquatic ecosystems polluted with heavy metals, may therefore threaten human nutrition and health directly. To measure the effects these substances could have on fish species and subsequently human populations, a histological investigation of the liver may produce meaningful and useful results.

Certain heavy metals are necessary for specific body functions due to their nutritional value. High concentrations of these metals can however cause a toxic effect within an organism. These toxic concentrations may vary in terms of the metal and specific species in question. This variation has been seen in mammals but also in various fish species. Previous studies indicated that these substances are harmful to fish, even in low concentrations. ${ }^{6}$

Fish are relatively sensitive to changes in their surrounding environment including an increase in pollution. Fish health may thus reflect, and give a good indication of the health status of a specific aquatic ecosystem.

The present study aims to document the toxicity of copper (Heavy Metal) in Catla catla fish. 


\section{MATERIALS AND METHODS}

\section{Study material}

For the present study fish, Catla catla was used. The fish was collected from the local ponds near Pattukkottai, Thanjavur, Tamil Nadu, South India were acclimatized to the laboratory conditions and feeding schedule.

\section{Bioassay test}

In a preliminary study the toxic and sublethal levels of heavy metals were found out for $48 \mathrm{hrs}$ exposures. A bioassay test is an experimental in which the concentration of a heavy metal were determined by the reaction of living organism to it. The bioassay tests were conducted to find out the LC50 values for different durations of exposure (24, 48,72 and 96 hours). Different concentrations of the heavy metals were taken in a cylindrical glass aquarium. The volume of the water in the glass aquaria was maintained as 20 litres. In each concentration of heavy metals 6 individuals were introduced and observed for fish mortality.

The fish were observed for behavioural changes and mortality at 24, 48, 72 and 96 hours of exposure were recorded and tabulated employing each of the four test media. The highest concentration at which 100 percent mortality was observed within 24 hours was considered as the lethal concentration ( $24 \mathrm{~h} \mathrm{LC100)}$ ) and the lowest concentration at which 100 percent survival was observed by the end of 96 hours was considered as the sublethal concentration (96 $\mathrm{h}$ LCO). The LC50, the lethal concentration, which kills $50 \%$ of individuals at $96 \mathrm{~h}$ exposure was found out by profit analysis. Thus, the sublethal LC50 and lethal concentrations of heavy metals were determined and the data obtained by profit analysis by the method of Finney (1978). Chi-square test was used to verify to homogeneity of the population selected for the present investigation by Busvine, (1971). ${ }^{7-10}$

\section{Heavy metal}

For these present study heavy metals copper was taken and this was prepared at $2 \mathrm{ppm}$ concentration.

\section{Feed}

Fishmeals were given to the fishes daily one hour from 10.00 A.M to 11.00 A.M. after that the left over fishmeals were removed with pipettes. The experiments were conducted for a period of 20 days. Water was changed in alternate days with freshly heavy metal treated (2 $\mathrm{ppm} /$ liter) in experimental tanks. Triplicate of the control and experimental ones were conducted simultaneously.

\section{Preparation of fish samples}

After 20 days of experiment 5 fishes from the control as well as the experimental set up were dissected out in saline $0.9 \%$ solution (Lockwood, 1971) to remove the muscle tissue and two fish were kept as such. They were taken in watch glass and allowed to dehydrate in an oven, maintained at 500C. After dehydration, they were powdered by grinding them with mortar and pestle and then preserved in small polythene bags for further use.

\section{Estimation of copper (Cu)}

\section{Reagents}

A. Ammonium hydroxide - specific gravity 0.90 .

B. Chloroform - AR grade.

C. Hydrochloric acid - concentrated.

D. Hydroxylamine hydrochloride solution: Prepared by dissolving $40 \mathrm{~g}$ of hydroxylamine hydrochloride in $200 \mathrm{ml}$ of distilled water.

E. Isopropyl alcohol.

F. Neocuproine solution: Prepared by dissolving $0.1 \mathrm{~g}$ of neocuproine in $50 \mathrm{ml}$ of isopropyl alcohol and diluted to $100 \mathrm{ml}$ with double distilled water.

G. Nitric acid - concentrated.

H. Sulphuric acid - concentrated.

I. Sodium citrate solution: Prepared by dissolving $250 \mathrm{~g}$ of hydrated sodium citrate in water and made upto $1000 \mathrm{ml}$. To this $10 \mathrm{ml}$ each of neocuproine solution and hydroxylamine hydrochloride solution were added. Impurities of copper were removed by extraction with chloroform, discarding the chloroform layer.

J. Stock copper II solution: Prepared by dissolving $0.2 \mathrm{~g}$ of pure copper metal by warming with $6 \mathrm{ml}$ of 1: 1 nitric acid. To this $1 \mathrm{ml}$ of conc. $\mathrm{H}_{2} \mathrm{SO} 4$ was added and the solution was evaporated to dryness. Then the residue was diluted to 1 litre with distilled water $\left(1 \mathrm{ml}=200 \mathrm{~g}^{-1}\right)$.

K. Intermediated copper II solution: Prepared by diluting $100 \mathrm{ml}$ of stock solution to 1 litre with distilled water $(1 \mathrm{ml}$ $=20 \mu \mathrm{g} 1^{-1}$ ).

L. Standard copper: Prepared by diluting $1 \mathrm{ml}$ of the intermediated stock solution to $50 \mathrm{ml}$ with distilled water $\left(1 \mathrm{ml}=0.4 \mu \mathrm{g} \mathrm{1^{-1 }}\right)$.

\section{Procedure}

To remove the interfering substances, $1 \mathrm{ml}$ of reagent $(\mathrm{H})$ and $5 \mathrm{ml}$ of reagent (G) were added and evaporated to dense white sulphur trioxide fumes on a hot plate. The treatment was repeated by adding $5 \mathrm{ml}$ each of reagent (G) and hydrogen peroxide and the solution was evaporated to complete dryness. Then the residue was dissolved in 80 $\mathrm{ml}$ of distilled water, boiled, cooled and filtered. The $\mathrm{pH}$ of the content was adjusted to 4 to 6 with dropwise addition of reagent (A). To the content $0.2 \mathrm{ml}$ of reagent $(C)$ was added and diluted to $100 \mathrm{ml}$ with distilled water.

\section{Extraction}

In a separating funnel, $50 \mathrm{ml}$ of acidified sample was taken. To this $5 \mathrm{ml}$ of reagent (D) and $10 \mathrm{ml}$ of reagent (F) were added and shaken well. To the contents $20 \mathrm{ml}$ of reagent (B) was added and shaken for 1 minute in order separate aqueous and chloroform layer. Chloroform layer 
was collected in a dry flask. This procedure was repeated with another $20 \mathrm{ml}$ aliquot of chloroform. Finally, the extracts were pooled and made up to $50 \mathrm{ml}$ with reagent (E). Reagent blank was prepared by treating $50 \mathrm{ml}$ of double distilled water in the same way as described above. The optical density of the sample solution was measured at $457 \mathrm{~nm}$ against the reagent blank. The amount of copper was calculated by using a calibration graph prepared from pure copper metal in the concentration range $0.05,0.1$, $0.5,1.0,5.0 \mathrm{mg}^{-1}$.

\section{Calculation}

Copper, $m g 1^{-1}=M / V \times 100$

Where,

$\mathrm{M}=$ mass in $\mathrm{mg}$ of copper in the sample and

$\mathrm{V}=$ volume of sample in $\mathrm{ml}$.

Histology - Paraffin methods (Humason, 1979)

\section{Reagents}

A. Physiological saline (0.9\%)

B. Bouin-Hollande fixatives

C. Ehrlich`s haematoxylin

D. Eosin

\section{Procedure}

Fish liver dissected from control and parallel experimental groups were blotted free of membrane washed in physiological saline, cut into pieces of desired size and fixed in Bouin's-Hollande fixative for 24 hours. After fixation, tissues were washed in $70 \%$ alcohol for three days to remove excess picric acid and dehydrated in graded series of alcohol. The tissues were infiltrated with molten paraffin at $58-600 \mathrm{C}$ through three changes (20-30 min each) and finally embedded in paraffin. $3-5 \mathrm{~mm}$ thick sections of all the tissue were obtained using a rotary microtome (Leica, Germany) and stained in Ehrlich`s haematoxylin with eosin as counter stain. The slides were mounted using DPX mountant. The sections were observed under a Nikon microscope in field illumination and chosen areas were photographed at x40, x100, x200, x450 and x1000 magnifications.

\section{RESULTS}

For the present study, the fish Catla catla were reared at their sublethal concentrations of heavy metals. On toxicity of heavy metal nearly same sublethal concentrations were selected in this study. The experiments were conducted during winter season. The conditions of the experiments were as follow the temperature ranged from 19.5 to $21.5^{\circ} \mathrm{C}, \mathrm{pH}$ ranged from 8.22 to 8.31 and dissolved oxygen varied from 4.38 to $4.97 \mathrm{mg} 1^{-1}$.

Acute toxicity tests of copper to Catla catla are shown in (Table 1). The present study recorded that 96h LC50 value of Cu was 2.0 ppm. Percentage of mortality exposed Catla catla varied copper concentration and exposure time
(Table 1). A concentration of 2-ppm copper was sublethal for $96 \mathrm{hrs}$ exposures but 10-ppm copper caused $100 \%$ mortality within $96 \mathrm{hrs}$ exposure (Lethal or Toxicity). The point at which the time best demise crossed $50 \%$ of mortality level was currency in the axis to identify LC50. The medium lethal concentration (LC50) for $24,48,72$, and $96 \mathrm{hrs}$ were found, as were 10, 8, 6, 4 and 2 ppm. The mortality of fish decreased with decreasing concentration of heavy metals of copper.

As soon as fishes were transferred from fresh water to lethal and sublethal concentrations of heavy metals of copper increased swimming activity was noted. At lethal concentration of heavy metals of copper the fishes showed erratic swimming activities and lost their balance.

Table 1: Effect of different concentration of copper on mortality percentage of Catla catla fish as a function of different exposure time.

\begin{tabular}{|c|c|c|c|c|}
\hline $\begin{array}{c}\text { Conc. of } \\
\text { copper (ppm) }\end{array}$ & \multicolumn{5}{|c|}{ Exposure time } \\
\hline 5 & $\mathbf{2 4} \mathbf{~ h r s}$ & $\mathbf{4 8} \mathbf{~ h r s}$ & $\mathbf{7 2} \mathbf{~ h r s}$ & $\mathbf{9 6} \mathbf{~ h r s}$ \\
\hline 4 & 60 & 70 & 90 & 100 \\
\hline 3 & 50 & 70 & 80 & 90 \\
\hline 2 & 30 & 50 & 60 & 80 \\
\hline 1 & 20 & 30 & 40 & 50 \\
\hline
\end{tabular}

\section{Histopathology of fish}

The liver was examined grossly, weighed and stored in formalin $10 \%$ and were processed for paraffin embedding using the standard micro technique. A section of the organs $(5 \mu \mathrm{m})$ stained with alumhemotoxylin and eosin was observed microscopically for histopathological studies.

Histopathologically, the control animals showed normal liver architecture, intense centrilobular necrosis, vacuolization and macrovesicular fatty changes (control Group I) Fig. 1-4.

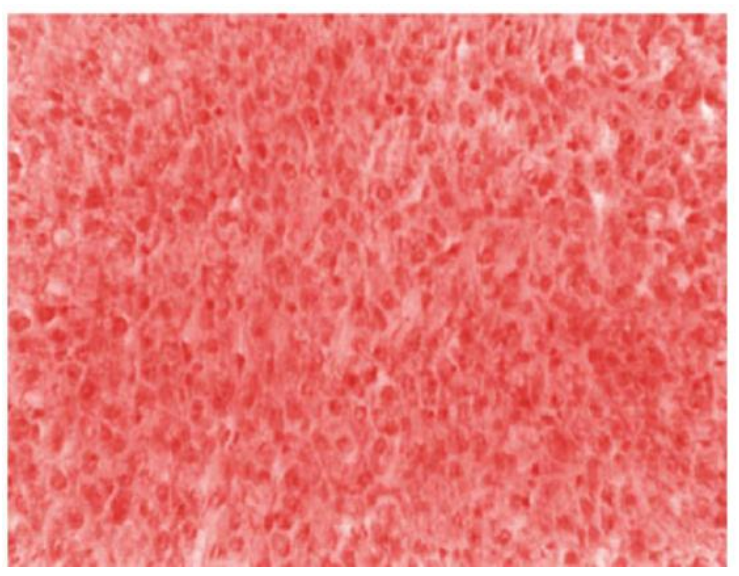

Figure 1: Control 


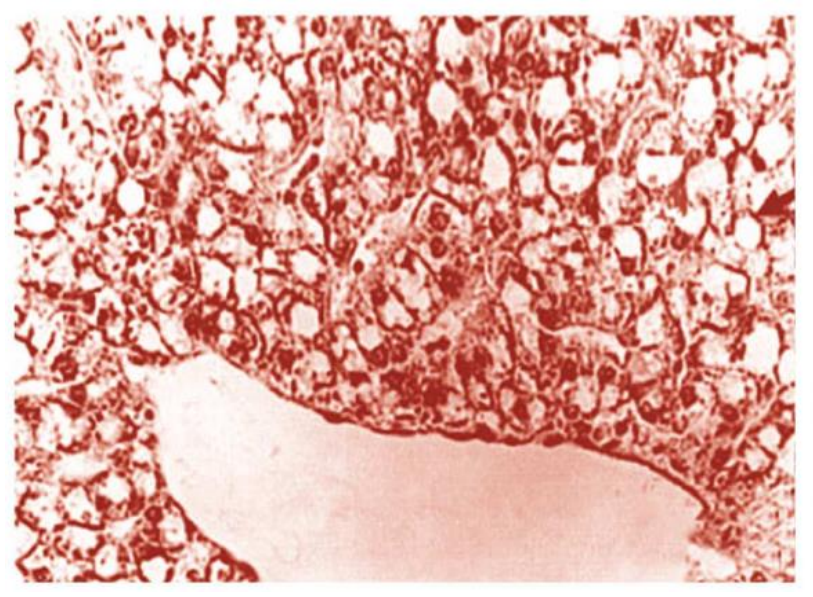

Figure 2: Copper treated fish

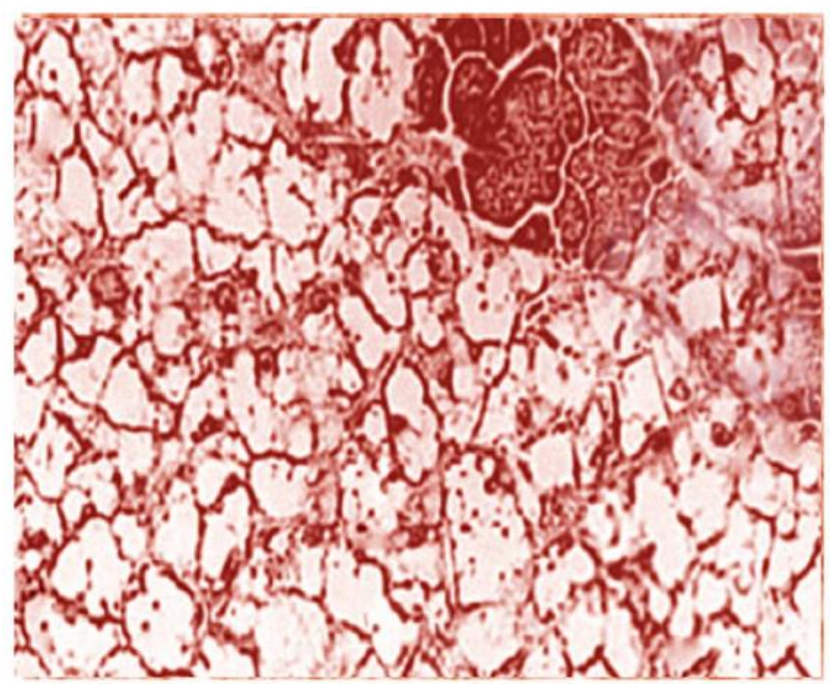

Figure 3: Pseudomonas treated fish

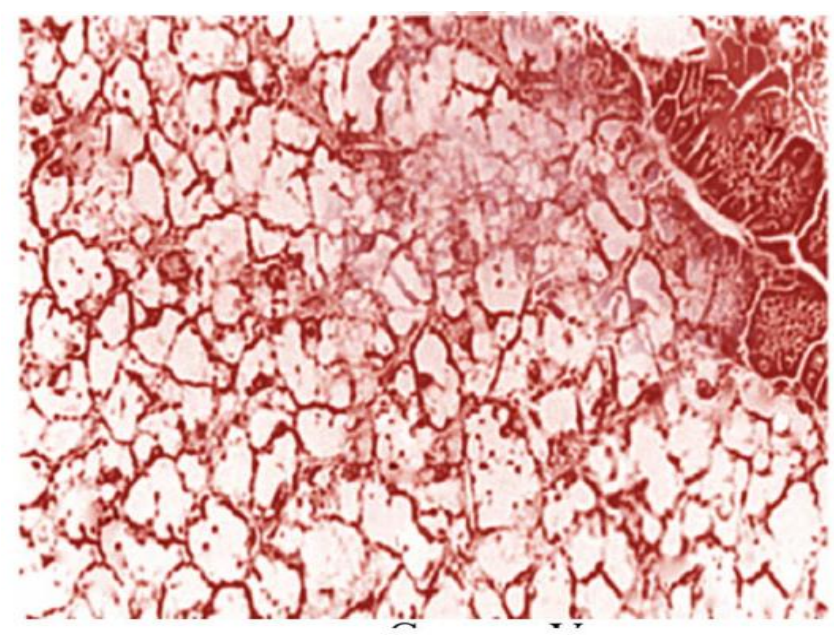

Figure 4: Copper and Pseudomonas treated fish

\section{DISCUSSION}

A summary of acute toxicity of copper to Catla catla and other fishes indicates that Catla catla is more susceptible to copper than other fishes (Table 1). The differences in the 96hrs LC50 values between Catla catla and other fishes may be attributed to the fact that metal induced changes in physiology and survival of aquatic organisms under metallic stress is complicated because such changes differ from metal to metal, species to species and from one experimental condition to another.

The exact causes of death due to heavy metal poisoning are multiple and depend mainly on time concentration combinations. However, there is no clear cut explanation on the exact mode of action of different metals causing the mortality in aquatic animals. It is possible that cumulative action of copper at various metabolic sites could be responsible for the mortality of Catla catla.

The $72 \mathrm{~h}$ LC50 of Cd for Mugil seheli was $4.87 \mathrm{mg} / 1 .^{7}$ Toxicity of $\mathrm{Cd}$ to Mugil seheli decreased with increasing the exposure time and the recording LC50 values were 12.34, $8.92,6.01$ and $3.45 \mathrm{mg} / \mathrm{l}$ for 24, 48, 72 and 96 hours, respectively. ${ }^{8}$

In the present study $96 \mathrm{~h}$ LC50 values of copper was 2.0 ppm for fish Catla catla.

LC50 values of about 0.3 to $50 \mathrm{mg} \mathrm{Cd} / 1$. While $96 \mathrm{~h} \mathrm{LC50}$ of Cu ranged from 0.2 to $3 \mathrm{mg} / 1$ for various marine fish and crustaceans. $^{9}$ The toxicity of copper, cadmium, lead and zinc to fishes. Table 1 depicts the percentage mortality for different exposure periods at different concentrations of copper. LC50 value of copper for the fish Catla catla was determined. ${ }^{10}$

The behaviour and mortality rate of Catla catla during our experimentation was found to depend on both duration of exposure and concentration of the toxicant. This is evident from the reported values of $96 \mathrm{hrs}$ LC50 for Poecili reticulata, which is $30.4 \mathrm{mg} / \mathrm{L}$ in a static bioassay test system and $43 \mathrm{mg} / \mathrm{L}$ for Uca rapax, ${ }^{11} 25 \mathrm{mg} / \mathrm{l}$ for scorpion fish, Scorpaena guttata. ${ }^{12}$ The effect of the metal also depends on the $\mathrm{pH}$, temperature and the type of the animal. Though the organisms survive the initial attack of toxins/pollutants because of their protective adaptations, the injuries caused by the progressive exposure even in small doses will get manifested at later stages when the organisms resistance weakens due to ageing. Also the condition and response of the test organism to the amount of metal penetrating into its body, the degree of retention and the rate of excretion influence the toxic effect of heavy metal.

Catla catla on in introduction to lethal concentration of copper showed abnormal behaviours such as excitation attempt to jump out of water, heavy mucus secretion, and rapid opercular movement such as behavioural changes may be due to osmatic imbalance which affects nervous system. The above symptoms of poisoning have also been investigated in Clarias batrachus when treated with alathion in B. stigma treated with carbaryl. ${ }^{13,14}$

As cited in the introduction there is a growing body of evidence to indicate that metal ions can exert some deleterious impacts on a number of tissues of fish Catla catla. For instances, copper concentration effect in vivo model is believed to be associated with lowered succinate dehydrogenase activity and $\mathrm{O} 2$ consumption. ${ }^{15}$ 


\section{CONCLUSION}

At lethal concentration (10 ppm) the fish Catla catla secreted excess mucous and lost its equilibrium followed by death. From these studies, it was evident that the rate of mortality increased with increasing concentration of heavy metals. Hundred percent mortality occurred at a concentration of 10-ppm copper. The fishes comfortably survived at a concentration of 2-ppm and below for more than a heavy metals. Therefore, this 2-ppm and below, is considered to be the sublethal or around sublethal concentration. However, complementary studies are necessary for a better understanding of its deleterious effects.

\section{REFERENCES}

1. WHO, Copper Environmental Health Criteria 200. IPCSInternational Programme on Chemical Safety, WHO, Geneva. 1998.

2. Li, J., Quabius, S.E., Wendelaar Bonga, S., Flick, G and Lock, R.A.C. Effects of water-borne copper on branchial chloride cells and $\mathrm{Na}+\mathrm{K}+-$ ATPase activities in Mozambique tilapia (Oreochromis mossambicus). Aquat. Toxicol. 1998;43(1):11.

3. Pelgrom, S., Lamers, L., Lock, R., Balm, P and Wendelaar Bonga, S. Integrated physiological response of tilapia, Orechromis mossambicus to sublethal copper exposure. Aquat. Toxicol. 1995;32:303-320.

4. Olojo, E.A.A., Olurin, K.B., Mbaka, G and Oluwemimo, A.D. Histopathology of the gill and liver tissues of the African catfish Clarias gariepinus exposed to lead. Afr. J. Biotech. 2005;4(1):117-122.

5. Kock, G., Triendl, M and Hofer, R. Seasonal patterns of metal accumulation in Arctic char (Salvelinus alpinus) from an oligotrophic Alpine lake related to temperature. Can. J. Fish. Aquat. Sci. 1996;53:780-786.

6. Meyers, T.R and Hendricks, J.D. A summary of tissue lesions in aquatic animals induced by controlled exposures to environmental contaminants, chemotherapeutic agents and potential carcinogens. Mar. Fish. Rev. 1982;44(12):1-17.

7. Hamed, M. A-F. Seawater quality at the northern part of the Gulf of Suez and the nearby area of the Suez Canal. Master Science Thesis, Faculty of Science, El- Mansoura University. 1992.

8. El-Moselhy, M. Toxicity of cadmium to the marine fish Mugil seheli and its accumulation in different tissues. Journal Egypt Academy Society. Environmental Development. 2001;2(1): 17-28.

9. Taylor, D., Maddock, B. G and Mance, G. The acute toxicity of nine "grey-list' metals to two marine fish species, Limanda limanda and Chelon labrosus. Aquatic. Toxicol. 1985;7:136144.

10. Pagenkopf, G. K. Metal ion speciation and toxicity in aquatic systems. Pages 101-118 in editor H. Sigel. Concepts on Metal Ion Toxicity.1986.

11. Zanders, IP and Rojas, WE. Salinity effects on cd accumulation in various tissues of the tropical fiddler crab Uca rapax. Environ. Pollution. 1996;94(3):293-299.

12. Brown, DA., Bay, SM., Alfafara, JF., Hershelman, GP and Rosenthal, KD. Detoxification/toxification of cadmium in scorpionfish (Scorpaena guttata): Acute exposure. Aquatic Toxicol. 1984;5(2):93-107.

13. Sharma, R.K and Agarwal, A. Role of reactive Oxygen species in male infertility. Urology. 1996;98(6):835-850.

14. Monoharan T and Subbiah GW. Toxic and sublethal effects of endosulfan on Barabar stigma. Proc Ind Acad Sci. 1982; p.523-532.

15. Radhakrishnaiah, K., Suresh, A and Sivaramkrishna, B. Effect of sublethal concentration of mercury and zinc on the energetics of a freshwater fish Cyprinus carpio (Linnaeus). Acta. Biol. Hung. 1993;44(4):375-385.

Source of Support: The author(s) received no financial support for the research, authorship, and/or publication of this article.

Conflict of Interest: The author(s) declared no potential conflicts of interest with respect to the research, authorship, and/or publication of this article.

For any question relates to this article, please reach us at: editor@globalresearchonline.net New manuscripts for publication can be submitted at: submit@globalresearchonline.net and submit_ijpsrr@rediffmail.com 